\title{
Adaptation to climate change of the French wine industry: a systemic approach - Main outcomes of the project LACCAVE
}

\author{
Nathalie Ollat ${ }^{1}$, Hervé Quénol ${ }^{2}$, Gérard Barbeau ${ }^{3}$, Cornelis van Leeuwen ${ }^{1}$, Philippe Darriet ${ }^{4}$, Inaki Garcia de \\ Cortazar Atauri ${ }^{5}$, Benjamin Bois ${ }^{6}$, Hernan Ojeda $^{7}$, Eric Duchêne ${ }^{8}$, Eric Lebon ${ }^{9}$, Philippe Vivin ${ }^{1}$, Laurent \\ Torregrosa $^{10}$, Jean-Marie Sablayrolles ${ }^{11}$, Geneviève Teil ${ }^{12}$, Philippe Lagacherie ${ }^{13}$, Eric Giraud-Héraud ${ }^{4}$, Patrick \\ Aigrain $^{14}$ and Jean-Marc Touzard ${ }^{15}$ \\ 1 : EGFV, ISVV-Bordeaux Sciences Agro-INRA- Bordeaux Univ, ISVV33140 Villenave d'Ornon, France, \\ 2 : LEGT, CNRS-Univ de Rennes, Place du Recteur Henri Le Moal, 35043 Rennes, France \\ 3 : UVV, INRA, 42 rue Georges Morel BP 60057, 49071 Beaucouzé, France \\ 4 : Laboratoire Enologie, ISVV-Univ Bordeaux, 33140 Villenave d'Ornon, France \\ 5 : AgroClim, INRA, Domaine Saint Paul, Site Agroparc, CS 40509 - 84914 Avignon, France \\ 6 : Institut Universitaire de la Vigne et du Vin - Université de Bourgogne, 21000 Dijon, France \\ 7 : Experimental Unit of Pech Rouge, INRA, 11430 Gruissan, France \\ 8 : SVQV, INRA-Univ Strasbourg, 28, rue de Herrlisheim, 68000 Colmar, France \\ 9: LEPSE, INRA-Supagro, 2, place Viala, 34060 Montpellier, France \\ 10 : AGAP, Univ. Montpellier, CIRAD, INRA,Supagro-, 2, place Viala, 34060 Montpellier, France \\ 11 : SPO, INRA-Supagro, 2, place Viala, 34060 Montpellier, France \\ 12 : SAD APT, INRA-Agroparitech, 16 rue Claude Bernard, 75005 Paris, France \\ 13 : LISAH, INRA-IRD-SupAgro, 2, place Pierre Viala, 34060 Montpellier, France \\ 14 : FranceAgriMer, Service Etude et Prospective, 93555, Montreuil, France \\ 15 : Innovation, INRA-Supagro, 2, place Viala, 34060 Montpellier, France
}

\begin{abstract}
Taking into account the major economical role and specificities of the French wine industry, adaptation to climate change is a very challenging issue. In 2011, 23 research teams launched a systemic and multidisciplinary program to analyze the impacts from the vine to the region, to define adaptation strategies combining technical, spatial and organizational options and to evaluate the perception by the actors and consumers of climate change issues. Thermal variability was studied at local scale to develop high resolution atmospheric models which better simulate future climate trends. Impacts on growth/developmental conditions and vine responses were estimated from the calculation of eco-climatic indices and a combination of functional models. Genetic and physiological bases of grapevine adaptation to high temperature and drought were analyzed. Improving oenological and cultural practices as well as plant material innovation have been investigated as major technical adaptations. How these options could be implemented at the plot level was examined to elaborate decision tools. Multi-agent modelling was developed for this purpose. Surveys were performed to evaluate the perception of the main actors regarding climate change and their level of acceptability towards technical changes. Consumer acceptability of new types of wines was also investigated with an experimental economy approach. Finally a foresight exercise was conducted to design four potential adaptation strategies: conservative, innovative, nomad and liberal. Outcomes of this exercise are now used as a tool for wine industry members to develop their own strategic plan for adaptation.
\end{abstract}

\section{1-General objectives}

The general objectives of the LACCAVE project are to further characterize the long-term impacts (2050) of climate change on the grapevine growing and wine production, particularly at regional scales, and to elaborate additional knowledge on innovations and possible adaptation strategies for the sector. The purpose is not to propose technical solutions ready to use. The goal is to improve our understanding of the effects of climate change, and then to explore various levers and their combinations to define adaptation strategies at the local or regional scale. It is also important to assess the economic, sociological and environmental consequences of these strategies. Finally it aims at coordinating the French research on these issues, at communicating the results at the national and international levels, in order to better meet the demand of the industry and society.

More specific objectives are i) to build a multidisciplinary scientific network, ii) to develop a shared vision and a collective questioning on the issue, iii) to develop methods and analysis tools, iv) to coordinate responses to other funding calls. The project 
has the ambition to support a set of targeted or integrative studies and achieve a prospective study on adaptation strategies. To prepare a more operational phase, the objective is also to share information and initiate actions with stakeholders.

\section{2- Overview of the results}

\section{1- The construction of a national scientific network}

LACCAVE brought together all the French teams working on the theme "vine, wine and climate change": 96 researchers and students, 20 INRA and 3 non INRA laboratories. The project improved the visibility of their work at national and international scale. This community exchanged very actively, taking into account the multidisciplinary dimension of the issue. Existing or new collaborations have been developed (leading in many cases to new formal projects). The LACCAVE members shared a systemic vision and analysis framework of adaptation (combination of adaptation levers at several scales, taking into account the perception by stakeholders and consumers). Workshops and thematic seminars, annual general assemblies of the participants, coordination board meetings, the foresight exercise and the organization of the international conference about sustainable grape and wine production in the context of climate change "ClimWine2016" managed to build this community of knowledge.

\subsection{The improvement of climate simulations at local level}

LACCAVE provided the framework for improving knowledge on climate variability and climate evolution at the local level. Climatologists and modelling specialists have worked on climate scenarios across a $8 \mathrm{~km}$ x $8 \mathrm{~km}$ grid developed by MétéoFrance and available on the DRIAS platform (http://www.drias-climat.fr/), in order i) to obtain useful information for the development of adaptation strategies in different French wine regions, and ii) to disseminate these outputs to stakeholders $[1,2$, 3]. Furthermore, temperature variability at local level has been studied in a modelling perspective in the Loire Valley [4] and the region of St Emilion [5]. These results highlight that within a small wine region, the variability of temperature can be equivalent to i) that observed on average between two wine regions, and ii) the increase in average temperature expected for 2050, offering flexibillity/opportunity for adaptation at the local level [6, 7].

\subsection{Overview of Climate Change impacts on vine and wine}

LACCAVE provided an overview of the impacts of climate change on vine and wine [8,9]. This synthesis has benefited from the collective ability to bring together results from a wide range of existing works, such as historical observations, experiments and simulations (in different disciplines). The advancement of phenological stages was confirmed and clarified $[1,3]$; the accentuation of water deficit for the vines in the Mediterranean area has been clearly shown [10]; the possible impacts of climate change on grapes component (sugar, acids, aroma precursors, anthocyanins ...) and the wine quality have been reviewed $[11,12,13]$, providing an illustration of how climate change can influence the quality of food, and thus its markets and regulations [14]. A survey has been launched at the international level, in order to better assess the correlations between disease incidence and climatic data, and to improve pest risk simulations [15]. They have mostly been a common basis to start working on adaptation, defined as a set of actions to respond these impacts [16].

\subsection{Advanced knowledge on the genetic basis of adaptation}

In connection with other projects, the genetic determinants of vine response to water stress and to high temperatures were assessed. Phenology (methods, genetic variability analysis, modelling) was analyzed in collaboration with the ACCAF-PERPHECLIM project. Genetic variability was studied in clonal populations, intraspecific vinifera or between rootstock genotypes [17, 18]. The results highlight the importance of hydraulic conductivity and night transpiration as genetically controlled characters involved in the management of water losses of the vine [19, 20, 21]. Furthermore, the metabolism of ABA and the molecular determinants of the transport of water in the plant have varying characteristics depending on the genetic origin of rootstocks, and could be associated with adaptation to drought [22]. Interactions between rootstock and scion play also a key role in the response of plants. The effect of high temperatures on i) the vegetative growth of the vine, ii) the berries and iii) the composition of the grapes has been studied. Variable and complex responses have been demonstrated according to the organ or molecule, and to the phenological stage impacted by the stress $[23$, $24,25]$. Studies carried out in the context of joint projects revealed significant interaction between the effects of $\mathrm{CO} 2$, temperature and UVB [26]. A major concerted effort was made on ecophysiological modelling in order to identify gaps and to better integrate the various existing models $[27,28]$.

\section{5- Characterization of adaptation practices in the vineyards}

Enological and viticultural practices, but also the potential of vine varieties (scion and rootstock) have been investigated as possible solutions for adaptation. In winemaking, yeast strains producing less alcohol have 
been selected in Montpellier and Bordeaux [29, 30]. Other technologies such as de-alcoholisation or acidification have also been experimented in the context of industrial partnerships. The management of the aromatic potential of wine in a context of climate change was also been analyzed and debated [31, 11]. As far as grapevine vine management is concerned, a wide range of practices has been assessed [32], including irrigation [33]. Research on highly innovative processes such as the use of recycled water for irrigation and coupling grapevine growing with the production of electricity by photovoltaic coverage have also been initiated. First results are promising and studies should continue.

The diversity of plant material (varieties and rootstocks) has been studied in different vineyards, using pre-existing experiments [34, 18]. A large experiment for rootstock assessment has been planted. These experiments have raised a significant amount of data on the phenology and ripening features of many varieties, but also on their agronomic and biochemical characteristics. Data have been stored in specific information systems for further analyses.

An overview of the possible changes of practices at different scales of space and time was conducted [32] and can be used as a decision making tool. Several surveys were also carried out among wine producers in different regions in order to assess their perceptions of both climate change and new practices $[35,36]$. Sociological surveys show how the changes in practices for the climate challenge are influenced by those related to environmental and quality issues [36]. Combined approaches with climate modelling at local level, assessment of impacts on grape growing, analysis of practices and perceptions of wine growers draw a methodological basis for exploring the best practices of adaptation at vineyard level.

\subsection{Land use management and modelling of landscapes evolution}

LACCAVE considered the local level as a key issue for adaptation [37], leading to reconsider the organization / location of the vineyard plots according to the variability of climate impacts and the management of local public goods (soil, water, landscape, biodiversity ...). To support these local strategies several methods have been explored combining scenario building, exploration of coordination problems and co-construction of strategies with stakeholders. Multi-agent models connected with cartographic representations (on climate and land use) and models integrating hydrological, agronomical and ecological processes were elaborated [38, 39]. For example, the simulations of future landscapes of Banyuls vineyards (extreme south of France) have linked climate change, land management and possible evolution of the wine quality (which depends on the location of the plots). The outputs have been elaborated and discussed with the grape growers of the local cooperative in order to explore new collective rules for vine plantation and grape payment [38].

\subsection{Economic analysis of conditions for adaptation to climate change.}

Beyond the theoretical assessments on the economic dimensions of adaptation in the wine industry [16], surveys have been carried out in the Bordeaux region, linking the perceptions of climate change by the wine producers with their expected strategies, and their potential costs at the farm level. In this regional context, producers are mainly considering the risks of climate variability [40], adopting different strategies according to their economic resources and their (inherited/projected) trajectory. Studies in other regions confirmed that risk management is crucial, combined with different local issues (drought in Languedoc, diseases in Champagne [36]. Economic decisions (investment) result from uncertain cost/benefice calculations, taking into account the wine value, the expected costs and a scope of options allowed by each quality label [41].

The analysis of consumer's willingness to pay for wines affected by climate change is a key contribution of LACCAVE. Methods of experimental economics were developed to show that consumer's behavior is also a lever for adaptation. Wine tasting sessions were organized with large consumers panels in order to assess their judgment and willingness to pay for wines (still) impacted by climate change (more alcohol, less acidity, changes in aroma and color) and wines produced with oenological innovations in order to correct the wine composition. The influences of climate change on several sensory characteristics of the wines have been demonstrated, suggesting influences on the (future) wines markets [42]. This work is an important scientific verification of the instability of consumer's preferences according to the length of exposure to a product [43]The "wines of climate change" were more appreciated in the first tasting session, but were progressively depreciated (in comparison to current wines) when the consumer repeated the tasting along a week. Finally the results show that consumers evaluate differently (partly related to age and gender) the oenological practices used to correct the effects of climate change on quality (dealcoholisation and acidification) [42].

\subsection{The role of innovations and research for adaptation}

Within LACCAVE, the role of agricultural research on the development and dissemination of innovations that contribute to adaptation strategies was investigated (new varieties, agronomic practices, wine-making technology...). A national survey, combined with a bibliometric study of scientific publications on "vine and wine", showed the importance of ongoing research (around the two poles of Montpellier and Bordeaux), but 
without clear relations with the regional vineyards where the research centers are located [44]. A double survey was thus carried out in 3 vineyards (Champagne, Bordeaux, Languedoc) with one hundred wine producers and 80 scientists in order to analyze the links between i) the perception of the climate challenge, ii) the implemented/expected actions coping with this challenge (in research or adoption of innovation) and iii) the advice networks built for these actions. If various wine producers profiles (according to their vision of innovations and climate change) are shared between the regions, their willingness to innovate largely depends on each "regional innovation system" [45] and the role played wine inter-professional organization, able to build a real "demand for research and innovation" [45]. These results call for developing multidisciplinary and participatory research, including the wine interprofessional partners [14]. They show that the organization of links between research and wine producers is also a lever for adaptation.

\subsection{The construction of adaptation scenarios for the vine and wine sector}

Finally LACCAVE launched a foresight exercise in order to explore potential adaptation strategies in the French wine industry, in the context of climate change. The exercise was led by a group of 12 LACCAVE participants (covering the full expertise range) and representatives of governmental bodies in charge of Appelation system (INAO) and Agriculture in general (FranceAgriMer). An original method was tested to describe the pathways leading to the implementation of different adaptation strategies [46]. Starting from a "median" climate scenario for 2050, 4 major adaptation strategies have been defined: "conservative" integrating marginal changes in the current vineyards; "Innovations to remain in place" opening the existing vineyards to radical innovations in order to maintain their current locations ; "Nomad vineyards" highlighting the consequences of potential vineyards relocation; "Liberal" testing a situation where "everything is possible everywhere." The group has collected, selected and combined a wide range of assumptions that could be related to these 4 strategies (influence-dependency matrix between 70 assumptions) and based on expert knowledge, previous foresight exercise and the survey described in 2.8. Four pathways were finally described by linking micro-scenarios (outputs of the matrix analysis), providing possible stories that lead to the 4 adaptation strategies in 2050. The 4 strategies were submitted to the industry in 6 different wine regions during participative workshops. Outcomes of this exercise and the workshops are currently used to initiate a new phase of coconstruction of "climate strategies" at local and national scales.

\section{Impacts and perspectives}

LACCAVE allowed to raise the awareness of the grape and wine industry about climate change, but also of policy makers. A stakeholder group has now been launched at national level to define a national plan for adaptation. LACCAVE also contributed to build a shared and systemic vision of adaptation among the French scientific community working on vine and wine. This shared vision is crucial to elaborate proper innovations for the actors. Communication towards various publics was very active in order to provide a scientific and realistic message about the expected impacts of climate change on this national industry [47]. It can be summarized as following:

- Adaptation strategies depend first on the level of mitigation and could be reasonably implemented in all French vineyards if global warming stays in the range of the current simulations made by climatologists for 2050 [48].

- There is no single and simple solution. Different levers including technical innovations, geographical strategies, and organisational changes, and regulation policies should be combined.

-Perception and adaptation capacities from the different stakeholders of the industry should be taken into account.

- Solutions should be integrated, by considering the value chain for wines, including the evaluation of consumer preferences. Global issues should also be taken into account as short-term challenges for the industry (lowering the pesticide inputs), other environmental aspects and public health considerations.

- These adaptation strategies must be coordinated at local and regional levels where climate impacts are specific and where the use of resources can be optimized;

- Taking into account the large uncertainties, the best way to adapt will be based on the collaborative capacity between researchers and stakeholders, even at regional level.

Perspectives of this first step are to further investigate effective solutions operating at different scales. Based on the knowledge already collected, challenging issues of adaptation as water management, pest management, soil management, better adapted varieties, vineyard location, wine quality and economic issues should be considered in a complex and systemic way. Simulated eco-climatic indicators and vine responses should be delivered to the industry in order to better define adaptation strategies and solutions. Participative activities with stakeholders should be launched in order to elaborate from national to estate levels adaptation plans and to design adapted and resilient cropping systems. Information systems should also be 
delivered to collect existing initiatives and innovations. Finally working at international levels should allow to learn from the experience of other wine regions and to share with them our analytical approach of adaptation. These perspectives will be developed with the new project LACCAVE 2.21.

\section{ACKNOWLEDGMENTS}

The authors would like to thank all the participants of LACCAVE and the contribution of stakeholders all through the project. Without their work, this paper and many others would not have been possible. We dedicate this contribution to our estimated colleague, friend and co-author Eric Lebon who passed away in December 2016. This work was supported by the LACCAVE and PERPHECLIM projects funded by the meta-program Adaptation of Agriculture and Forests to Climate Change (AAFCC) of the French National Institute for Agricultural Research (INRA).

\section{REFERENCES}

1. B. Bois, I. Garcia de Cortazar-Atauri, H. Quénol, J. Caubel, Mid-term LACCAVE meeting Montpellier (2014)

2. E. Lebon, I. Garcia de Cortazar Atauri, Innov. Agron. INRA, Montpellier, pp 1-12 (2014)

3. I. García de Cortázar-Atauri, E. Duchêne, A. DestracIrvine, G. Barbeau, L. de Rességuier, T. Lacombe, A.K. Parker, N. Saurin, C.van Leeuwen, OenoOne, 51: 115 (2017)

4. E. Neethling, T. Petitjean, H. Quénol, G. Barbeau, Mitig Adapt Strateg Glob Change. DOI 10.1007/s11027-015-9698-0 (2016)

5. L. de Resseguier, R. Le Roux, H. Quénol, C. van Leeuwen, Proceedings of Clim Wine2016, 66 (2017)

6. C. Bonnefoy, M. Madelin, H. Quénol, Revue Internationale de Géomatique, 24/3, 377 (2014)

7. E. Neethling, T. Petitjean, H. Quénol, G. Barbeau, Mitig Adapt Strateg Glob Change. DOI 10.1007/s11027-015-9698-0 (2016)

8. N. Ollat, J.M. Touzard, J. I. S. V. V LACCAVE special issue, 1-7 (2014)

9. N. Ollat, J.M. Touzard, I. Garcia de Cortazar-Atauri, H. Quénol, C. van Leeuwen, Proceedings of ClimWine2016 (2017)

10. H. Ojeda, N. Saurin 2014. Innov. Agron., 38, 97 (2014)

11. P. Darriet, A. Pons, L. Allamy, A. Schüttler, C. van Leeuwen, C. Thibon, $3^{\text {ième }}$ assise des vins du Sud Ouest, Colloque IFV, (2016)

12. C. van Leeuwen, A. Destrac, OENO One, 51, 147 (2017)

13. E. Duchêne, G. Butterlin, P. Claudel, N. Jaegli

https://www.researchgate.net/publication/306941071_Co nsequences of elevated temperatures during_ripeni ng_on the biosynthesis_of monoterpenols_in_grape berries (2016)

14. N. Ollat, J.M. Touzard, C. van Leeuwen, J. Wine Economics 11, 139 (2016)

15. B. Bois, S. Zito, A. Calonnec, OENO one, 51,133 (2017)

16. V. Viguier, F. Lecocq, J.M. Touzard, J.I.S.V.V. Laccave Special issue, 55 (2014)

17. A. Bigard, D.T. Berhe, E. Maoddi, Y. Sire, J.M. Boursiquot, H. Ojeda, J.P. Péros, A.Doligez, C. Romieu, L. Torregrosa (2018) Vitis vinifera L. fruit diversity to breed varieties anticipating climate changes. Frontiers Plant Sci. doi: 10.3389/fpls.2018.00455.

18. E. M. Wolkovich, I. García de Cortázar-Atauri, I. Morales-Castilla, K. A. Nicholas, T. Lacombe. Nature Climate Change, 8, 29 (2018)

19. A. Coupel-Ledru, E. Lebon, A. Christophe, A. Doligez, L. Cabrera-Bosquet, P. Péchier, P. Hamard, P. This, T. Simonneau, J. Exp. Bot. 65: 6205 (2014)

20. A. Coupel-Ledru, E. Lebon, A. Christophe, A. Gallo, P. Gago, F. Pantin, A. Doligez, T. Simonneau, PNAS DOI: $10.1073 /$ pnas. 1600826113 (2016)

21. A. Coupel-Ledru, S. Tyerman, D. Masclef, E. Lebon, A. Christophe, E. Edwards, T. Simonneau Plant physiol. 175, 1121 (2017)

22. L. Rossdeutsch, E. Edwards, S.J. Cookson, F. Barrieu, G.A. Gambetta, S. Delrot, N. Ollat(2016) BMC Plant Biology, 16, 91 (2016)

23. L. Torregrosa L, A. Bigard, A. Doligez, D. Lecourieux, M. Rienth, N. Luchaire, P. Pieri, R. Chatbanyong, R. Shahood, M. Farnos, C. Roux, A. Adiveze, J. Pillet, Y. Sire, E. Zumstein, M. Veyret, L. Le Cunff, F. Lecourieux, N. Saurin, B. Muller, H. Ojeda, C. Houel, J-P Péros, P. This, A. Pellegrino, C. Romieu, OENO One, 51, 155 (2017)

24. E. Duchêne, OENO One, 50, DOI: 10.20870/oenoone.2016.50.3.98 (2016)

25. F. Lecourieux, C. Kappel, P. Pieri, J. Charon, J. Pillet, G. Hilbert, C. Renaud, E. Gomès, S. Delrot, D. Lecourieux, Frontiers in Plant Science 8 (2017)

26. J. Martínez-Lüscher, F. Morales, M. Sánchez-Díaz, S. Delrot, J. Aguirreolea, E. Gomès, I. Pascual (2015) Plant Sci, 236,168 (2015)

27. P. Vivin, E. Lebon, Z. Dai, E. Duchêne, M. Marguerit, I. García de Cortázar-Atauri, J. Zhu, T. Simonneau, C. van Leeuwe, S. Delrot, N. Ollat, OenoOne 51, 181 (2017)

28. J. Zhu, Z. Dai, P. Vivin, G. A. Gambetta, M. Henke, A. Peccoux, N. Ollat, S. Delrot, Annals of Botany, DOI:10.1093/aob/mcx141 (2017)

29. V. Tilloy, A. Ortiz-Julien, S. Dequin, Applied and Env. Microbiology, 80 : 2623 (2014)

30. S. Dequin, J.L. Escudier, M. Bely, J. Noble, W. Albertin, I. Masneuf-Pomarède, P. Marullo, J.M. Salmon, J.M. Sablayrolles, OENO One, 51, 205 (2017)

31. A. Pons, L. Allamy, A. Schüttler, C. Thibon, P. Darriet, OENO One, 51, 141 (2017)

32. G. Barbeau, E. Goulet, E. Neethling, N. Ollat, J.M. Touzard, Changement climatique et terroirs viticoles (2014) 
33. H. Ojeda, N. Saurin, S. Alvarez Gei, R. Symoneaux, C. Coulon-Leroy, Proceedings of ClimWine2016, 194 (2017)

34. A. Destrac, C. van Leeuwen, Proceedings of ClimWine2016, 166 (2017)

35. E. Neethling, T. Petitjean, H. Quénol, G. Barbeau, Mitig. Adapt. Strateg. Glob. Change, 22, 777 (2017)

36. G. Teil, Proceedings of ClimWine2016, 229 (2017)

37. H. Quénol, Pour une géographie de la conservation: Biodiversités, natures et sociétés (2015)

38. E. Delay, N. Becu, Proceedings of ClimWine2016, 204 (2017)

39. F. Vinatier, A. González Arnaiz, P. Lagacherie, Proceedings of ClimWine2016, 213 (2017)

40. A. Alonso Ugaglia, E. Giraud-Heraud, S. Pérès, Y. Surry,https://www6.inra.fr/laccave/ClimWine2016/D ownload-oral-presentations/Session-Perception-andadaptability-of-climate-change-by-the-actors (2016)

41. J. Boyer, J.-M. Touzard, Forum Innovation, Paris, Cité des Sciences et de l'Industrie (2016)
42. A. Fuentes-Espinoza, S. Pérès, A. Pons, S. Tempère, A. Samson, J.L. Escudier, P. Darriet, E. GiraudHéraud, Proceedings of ClimWine2016, 235 (2017)

43. E. Giraud-Héraud, Enometrics XXIII, COLMAR FR : May 25-28, (2016)

44. J. Boyer, J. M. Touzard, Proceedings of ClimWine2016, 235 (2017)

45. J. Boyer, Revue d'Economie et de Management de l'Innovation, 52 (2016)

46. P. Aigrain, B. Bois, F. Brugière, E. Duchêne, I. Garcia de Cortazar Atauri, J. Gautier, E. GiraudHéraud, H. Hannin, N. Ollat, J.M.Touzard, Proceedings of ClimWine2016, 253 (2017)

47. J.M. Touzard, N. Ollat N., Revue Parlementaire, 543 (2015)

48. IPCC - The physical Science Basis - Summary for Policymakers (2013) 